\title{
Second-order conditioning detects unexpressed morphine-induced salt aversion
}

\author{
RICK A. BEVINS, TIMOTHY A. DELZER, and MICHAEL T. BARDO \\ University of Kentucky, Lexington, Kentucky
}

\begin{abstract}
Morphine failed to condition a salt taste aversion at a dose ( $15 \mathrm{mg} / \mathrm{kg})$ sufficient to produce a robust aversion to a saccharin taste. Indeed, three different concentrations of salt $(1 \%, 1.5 \%$, and $2 \%)$ paired with the same morphine dose yielded no direct evidence for conditioned aversion. Yet, when a novel saccharin taste was paired in compound with the previously conditioned salt conditioned stimulus, we found evidence for a conditioning to the saccharin cue alone in three separate experiments. Control groups eliminated alternative accounts such as neophobia and differential exposure to morphine. Combined, these findings indicate that morphine conditioned a salt aversion. Although this aversion was not directly expressed, a second-order conditioning procedure was able to provide a more sensitive index of conditioning.
\end{abstract}

In the conditioned taste aversion preparation, a taste conditioned stimulus (CS) is paired with an illnessinducing unconditioned stimulus (US) such as $\mathrm{LiCl}$ or radiation. The use of this preparation by researchers has made important contributions to the fields of animal learning, psychopharmacology, pharmacology, toxicology, and biomedicine. For example, the taste aversion preparation has been used extensively in pharmacology and psychopharmacology to assess factors important in the acquisition of taste aversion and in the development of tolerance to the aversive properties of drugs of abuse (Cappell \& LeBlanc, 1975; Gamzu, Vincent, \& Boff, 1985; Iwamoto \& Williamson, 1984; Wise, Yokel, \& DeWit, 1976).

The use of the conditioned taste aversion preparation has also prompted important advances in the field of animal learning. A classic example is the work by Garcia and Koelling (1966), who repo:ted that the conditioned strength acquired by a CS was, in part, due to the interaction between the type of CS and US employed. That work spawned much research on CS-US interactions and theoretical debate on the generality of learning principles (e.g., Bevins, 1992; LoLordo, 1979; LoLordo \& Droungas, 1989; V. Miller, 1984; Seligman, 1970; Shettleworth, 1972).

Although some investigators have systematically examined taste qualities in the taste aversion preparation (e.g., Dugas du Villard, Her, \& MacLeod, 1981; Nowlis, Frank, \& Pfaffmann, 1980), most of this work has used saccharin as the taste CS (Hunt \& Amit, 1987; Riley \&

This work was supported by funds from U.S. Public Health Service Grant DA05623 to R.A.B. and DA05312 and DA07746 to M.T.B. We thank Philipp J. Kraemer for his comments on an earlier version of this manuscript. We also express our appreciation for the technical assistance provided by Melinda Marion. Correspondence should be addressed to R. A. Bevins, University of Kentucky, Department of Psychology, Kastle Hall, Lexington, KY 40506-0044 (e-mail: rabevi00@ukcc.uky.edu).
Clarke, 1977). The present series of experiments was initiated by an attempt in our laboratory to examine the ability of a salt cue, as well as a saccharin cue, to serve as a $\mathrm{CS}$ in a taste conditioning and analgesia preparation using morphine as the illness-inducing US (see, e.g., Bardo \& Valone, 1994; Bevins, Valone, Bradley, \& Bardo, 1995; J. S. Miller, Kelly, Neisewander, McCoy, \& Bardo, 1990). Taste aversion developed readily to a saccharin CS, but not to a salt CS repeatedly paired with a high dose of morphine. This initial observation is described as Experiment 1 below.

\section{EXPERIMENT 1}

\section{Method}

\section{Subjects}

The subjects were 36 male albino Sprague-Dawley rats, 200-225 g on arrival from Harlan Industries (Indianapolis, IN). Each rat was housed in a hanging stainless-steel wire-mesh cage. The colony room was on a 12:12-h light:dark cycle, and all experiments were run during the light part of the cycle. Food was available continuously in the home cages, but fluid access was restricted as described below. Rats were handled once on at least 2 separate days before the start of the study.

\section{Apparatus and Drugs}

All fluid presentations occurred in $24.5 \times 17.5 \times 17.5 \mathrm{~cm}(1 \times$ $\mathrm{w} \times \mathrm{h}$ ) mesh cages similar to the home cages. Mounted on the front of each cage was a 100-ml graduated drinking tube. These tubes permitted fluid consumption to be measured to the nearest milliliter. Because this study was originally designed to examine conditioned analgesia, a hot-plate apparatus was used (for description, see Bardo \& Valone, 1994)

Morphine sulfate from the National Institute on Drug Abuse (Rockville, MD) was diluted in physiological saline $(0.9 \% \mathrm{NaCl})$. The dosage of $15 \mathrm{mg} / \mathrm{kg}$ was calculated using the salt form of the drug. All morphine injections were subcutaneous (s.c.).

\section{Procedure}

Rats were water deprived for 6 days prior to conditioning. On these days, they received 15-min access to water in the rack of cages with the drinking tubes. After the 6th day, rats were randomly as- 
signed to one of four groups ( $n=9$ per group) with the stipulation that water intake on Day 6 did not differ statistically among groups. On Day 7 , rats were given the first of three conditioning trials. For half the rats, conditioning entailed 15 -min access to a $0.1 \%$ sodiumsaccharin solution $(\mathrm{w} / \mathrm{v})$, whereas the other half received access to a $1 \%$ salt solution $(w / v)$. Half the rats exposed to a given solution were injected with morphine $(15 \mathrm{mg} / \mathrm{kg})$ immediately following fluid consumption. The other half received a similar volume of saline injected SC. Thirty minutes after the injection, each rat was placed on the inactive hot plate for $60 \mathrm{sec}$. On the next 2 days (Days 8 and 9), rats received 15-min access to water without an injection. Days 7, 8, and 9 were repeated for two more conditioning trials. A CS-alone test was conducted on the day after the last intervening water day. The rats were given $15-\mathrm{min}$ access to the appropriate taste $\mathrm{CS}$ followed immediately by an injection of saline. Each rat was then placed on the active hot plate $\left(54^{\circ} \mathrm{C}\right) 30 \mathrm{~min}$ after exposure to the taste CS. Rats in the salt groups were given three additional conditioning trials and a second salt-alone test similar in detail to that just described.

\section{Data Analysis}

Because conditioning of the salt CS continued for an additional three trials, intake for each fluid type was analyzed separately using between-groups analyses of variance (ANOVAs). For all statistical tests in this report we used a two-tailed rejection region of .05 .

\section{Results}

The left panel of Figure 1 shows the mean amount of fluid consumed for each treatment group on the first CSalone test. Rats that received saccharin paired with morphine consumed less than the saline-treated rats $[F(1,16)$ $=29.76]$. However, the amount consumed by the group that received salt paired with morphine did not differ statistically from the saline control group $[F(1,16)=3.71$, $p=.07]$.

Given the trend for morphine-induced salt aversion, three additional trials were given in an attempt to strengthen

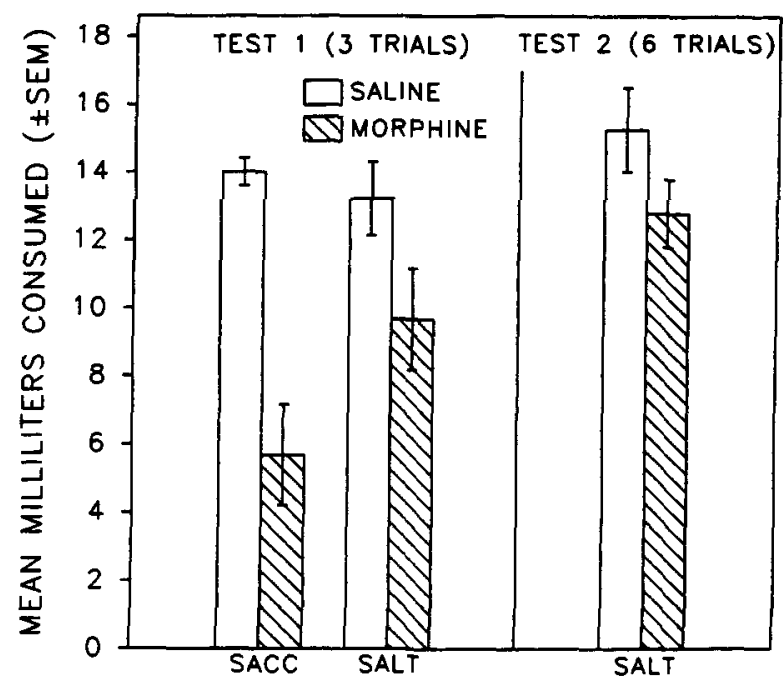

Figure 1. The left panel shows the mean amount of fluid consumed (1\% salt or $0.1 \%$ saccharin [SACC]) for each treatment group on the first conditioned-stimulus-alone test in Experiment 1 . The right panel shows the salt consumption data on the second test. conditioning to the salt cue. The right panel of Figure 1 shows the salt consumption data on the second salt-alone test. The additional salt-morphine pairings did not enhance the tendency for a salt aversion $[F(1,15)=2.47$, $p=.14] .{ }^{1}$ If anything, that tendency was weakened with continued training.

\section{Discussion}

The morphine-induced taste aversion using a $0.1 \%$ saccharin solution replicated past work from our laboratory (Bardo \& Valone, 1994; Bevins et al., 1995; J. S. Miller et al., 1990) and others (Cappell, LeBlanc, \& Endrenyi, 1973; Van der Kooy \& Phillips, 1977). However, the failure to find taste aversion to the $1 \%$ salt solution was surprising. The saccharin results clearly indicate that $15 \mathrm{mg} / \mathrm{kg}$ morphine was sufficient to condition a taste aversion. Furthermore, Bardo and Valone (1994) found saccharin taste aversion in three trials using a dose of morphine as low as $3 \mathrm{mg} / \mathrm{kg}$ (see also Cappell et al., 1973). It may be that the salt concentration was not high (salient) enough to be conditioned (Kalat \& Rozin, 1970; Rescorla \& Wagner, 1972). This account seems unlikely given the extent of the literature demonstrating conditioned taste aversion when a salt solution of $1 \%$ or less is paired with other USs such as $\mathrm{LiCl}$ (see, e.g., Bouton, Dunlap, \& Swartzentruber, 1987; Kalat \& Rozin, 1970; Schachtman, Kasprow, Meyer, Bourne, \& Hart, 1992; Yamamoto, Shimura, Sako, Yasoshima, \& Sakai, 1994b). Drugs of abuse like morphine are thought to induce taste aversion through different neural mechanisms than predominantly emetic drugs such as $\mathrm{LiCl}$ (see, e.g., Hunt \& Amit, 1987; Riley, Jacobs, \& LoLordo, 1978; Swank, Schafe, \& Bernstein, 1995; Yamamoto, Shimura, Sako, Yasoshima, \& Sakai, 1994a). Perhaps this different system requires higher salt concentrations than $\mathrm{LiCl}$ does to induce a conditioned aversion. In Experiment 2 we assessed this possibility by using two higher salt concentrations as the CS.

\section{EXPERIMENT 2}

Experiment 2 had two main goals: (1) to assess the role of salience of the salt CS in the failure to find morphineconditioned salt aversion by pairing either a $1.5 \%$ or a $2 \%$ salt solution with the morphine US, and (2) to determine if a second-order conditioning procedure (Pavlov, 1927) would reveal morphine-conditioned salt aversion if it was not expressed directly in the salt-conditioning phase. A growing body of literature indicates that apparent learning deficits are instead performance failures (see R. R. Miller \& Grahame, 1991). The second-order conditioning procedure is one possible tool for detecting unexpressed learning (i.e., performance failures).

The second-order conditioning procedure used here entailed three phases. In Phase 1, the salt CS was paired with the morphine US. In Phase 2, a new CS (saccharin) was presented in compound with the previously conditioned salt CS. In Phase 3, the conditioned strength ac- 
quired by the saccharin CS in Phase 2 was assessed by presenting the saccharin taste alone. If salt acquired some conditioned strength in Phase 1, taste aversion should be observed to the second-order saccharin CS in Phase 3.

\section{Method \\ Subjects and Apparatus \\ The subjects were 32 male Sprague-Dawley rats (250-298 g) housed and maintained like those in Experiment 1. Before the start of the present experiment, the rats had served in an experiment ex- amining the rats' behaviors in a novel environment. The rats were completely drug naive at the start of the present experiment. The wire-mesh cages with the mounted drinking tubes were similar to those of Experiment 1.}

\section{Procedure}

Initial training. Rats were water deprived for 3 days prior to conditioning. On these days, they received $15-\mathrm{min}$ access to water in the rack of cages. After Day 3, rats were assigned to one of four groups ( $n=8$ per group) with the stipulation that water intake on Day 3 did not differ statistically between groups.

Salt conditioning. On Day 4, rats were given the first of four conditioning trials. For half the rats, conditioning entailed 15 -min access to a $1.5 \%$ salt solution $(\mathrm{w} / \mathrm{v})$; the other half received access to a $2 \%$ salt solution $(w / v)$. Immediately following fluid presentation, half the rats received morphine $(15 \mathrm{mg} / \mathrm{kg})$ at each salt concentration; the other half received saline. On the following day (Day 5), rats received 15-min access to water without an injection. Days 4 and 5 were repeated for the remaining three conditioning trials.

Second-order conditioning. Salt conditioning was followed by 2 consecutive days of second-order conditioning. On each day, rats received 15 -min access to a cocktail solution containing $0.1 \%$ saccharin and the previously experienced salt concentration $(1.5 \%$ or $2 \%)$.

Saccharin test. After second-order conditioning, rats received two saccharin tests in which a $0.1 \%$ saccharin solution was presented for $15 \mathrm{~min}$. All rats received a $15-\mathrm{mg} / \mathrm{kg}$ injection of morphine immediately following fluid access on the 1 st test day. Two days of $15-$ min access to water separated the first and second saccharin tests.

\section{Results}

Salt conditioning. No evidence for morphineconditioned taste aversion was found at either salt concentration. The top panel of Figure 2 shows the consumption data from the last conditioning trial. The left part of this panel shows the $1.5 \%$ salt cue and the right part shows the $2 \%$ salt cue. A $2 \times 2$ analysis of variance (ANOVA) revealed a main effect of salt concentration $[F(1,28)=15.00]$, denoting an overall lower consumption of the $2 \%$ salt solution. The main effect of drug and the solution $\times$ drug interaction were not significant $(F \mathrm{~s}<1)$.

Second-order conditioning. The bottom panel of Figure 2 shows the intake data for the second-order conditioning phase in which the $0.1 \%$ saccharin was presented in compound with the appropriate salt concentration. For both trials there was a main effect of salt concentration $[F \mathrm{~s}(1,28) \geq 13.30]$, indicating lower intake of the $0.1 \%$ saccharin $+2 \%$ salt solution. Moreover, morphine-treated rats drank significantly less than did saline-treated rats on each second-order conditioning trial $[F \mathrm{~s}(1,28) \geq 15.66]$. The solution $\times$ drug interaction was not significant for either trial $(F \mathrm{~s}<1)$.
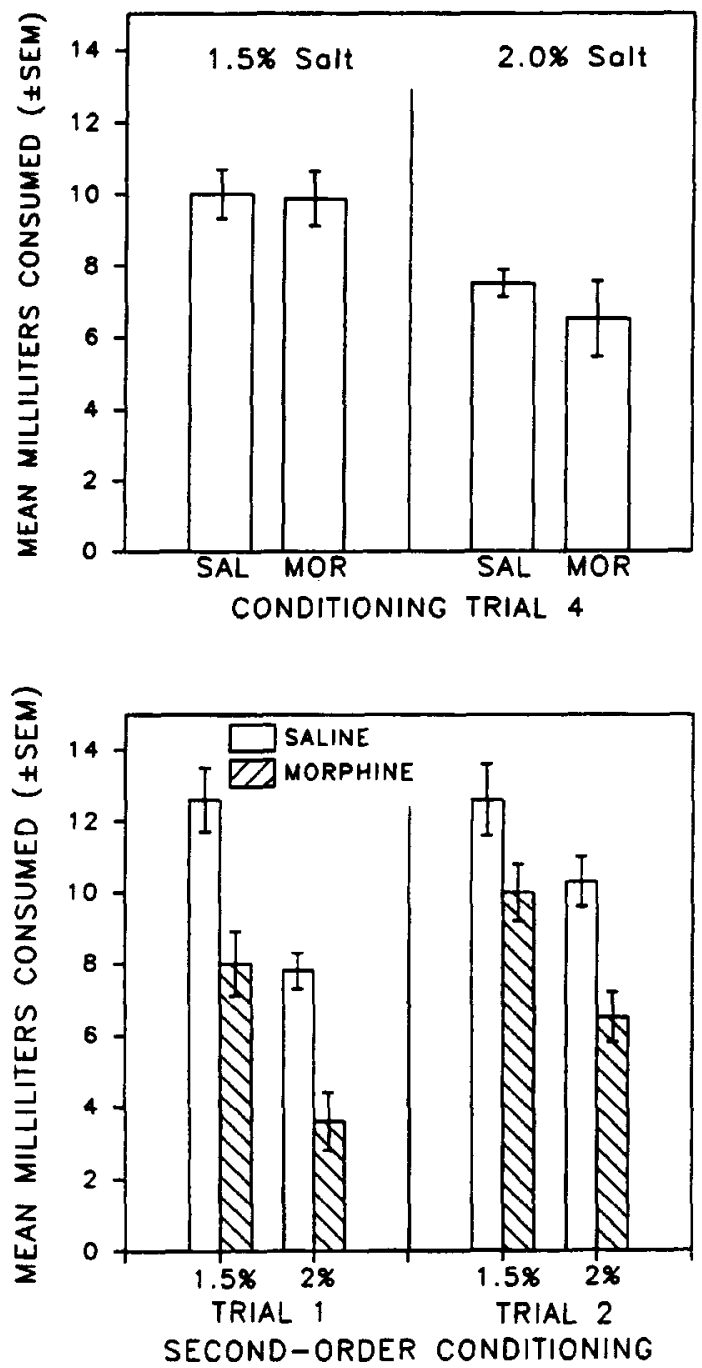

Figure 2. The top panel shows the consumption data from the last salt-conditioning trial in Experiment 2. The left part of this panel shows the $1.5 \%$ salt cue and the right part shows the $2 \%$ salt cue. The bottom panel shows the salt + saccharin intake data for the second-order conditioning phase.

Saccharin test. Evidence for second-order conditioning was found on the first saccharin test day. Rats that had the salt cue previously paired with morphine drank less saccharin solution than did rats that were treated with saline (left panel of Figure 3). A $2 \times 2$ ANOVA on the 1 st test day supported this observation with a significant main effect of drug $[F(1,28)=5.61]$. There was also a main effect of salt concentration previously experienced $[F(1,28)=5.61]$. The interaction was not significant $(F<1)$. The right panel of Figure 3 shows the intake data on the second saccharin test. Recall that all rats received an injection of morphine immediately after the first saccharin test. This single saccharin-morphine pairing reversed the data pattern. That is, morphine-naive rats (i.e., saline treated) consumed significantly less saccharin (greater aversion) than did rats previously treated with 


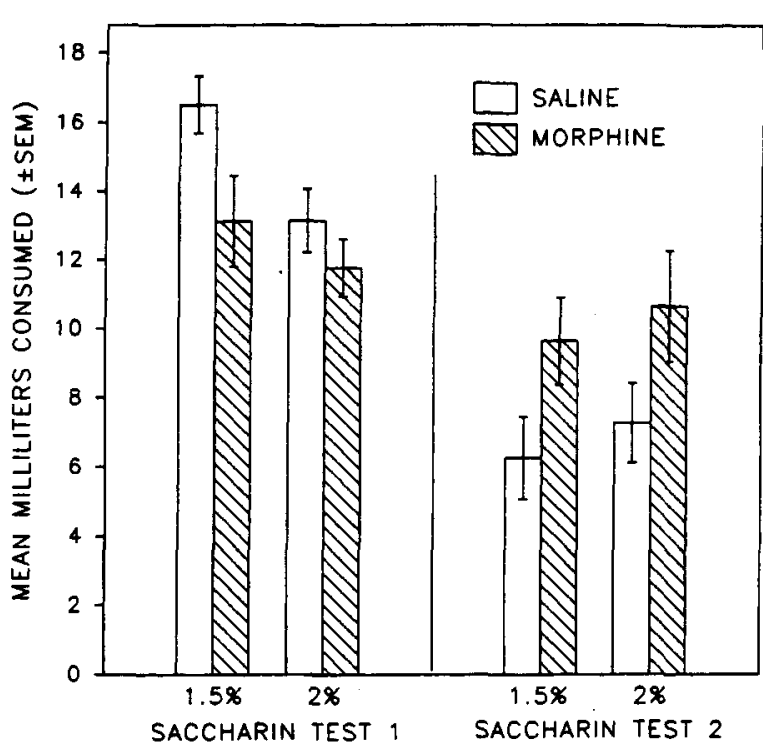

Figure 3. The consumption data for the test of second-order conditioning to the saccharin taste in Experiment 2. The first saccharin test is displayed in the left panel; the second test following a single saccharin-morphine pairing is shown in the right panel.

morphine $[F(1,28)=6.56]$. Neither the main effect of salt concentration nor the interaction was significant $(F \mathrm{~s}<1)$.

\section{Discussion}

The failure to find morphine-conditioned taste aversion to the salt CS in Experiment 1 does not appear to have been due to weak salience of the salt cue, since Experiment 2 also failed to find direct evidence for morphineinduced aversion when higher salt concentrations were used $(1.5 \%$ and $2 \%)$. These concentrations were well above the range that has been shown to be discriminable from water and that can acquire aversion when paired with an illness-inducing US such as $\mathrm{LiCl}$ (Bouton et al., 1987; Yamamoto et al., 1994b). Moreover, the second-order conditioning results and the fact that rats given the $2 \%$ salt cue drank less solution than did rats in the $1.5 \%$ condition suggests that the rats detected the salt concentrations.

Although the direct test did not detect conditioned salt aversion, the second-order conditioning procedure did reveal evidence for salt aversion. The lower saccharin intake by morphine-paired rats on the 1 st saccharin-alone test day may reflect the acquisition of conditioned aversive properties to the saccharin cue by virtue of being paired with the previously conditioned salt CS. Although the fluid $\times$ drug interaction was not significant, the $1.5 \%$ group appeared to show stronger second-order conditioning than did the $2 \%$ group.

The data pattern of the second saccharin test is surprising for a second-order conditioning account. That account predicts faster acquisition of conditioning to the saccharin cue previously presented with the morphinepaired salt CS. However, we found a stronger saccharin taste aversion following one morphine pairing in the drug-naive rats. This effect probably reflects the development of tolerance to the aversive properties of morphine in rats previously treated with this drug (Cappell \& LeBlanc, 1977; Stewart \& Eikelboom, 1978). Thus, morphine was a more potent US for saline-treated rats.

The second-order conditioning evidence for salt aversion has at least two nonassociative explanations. First, an account based on rats' tendency to be neophobic when presented with an unfamiliar taste (e.g., Domjan, 1977) may account for the saccharin-alone data. Recall that rats treated with morphine consumed less of the saccharin + salt compound than did the saline-treated rats. This outcome resulted in the morphine-paired rats receiving less exposure to the saccharin component. Thus, the saccharin would be more novel for morphine-treated rats relative to saline-treated rats and result in less saccharin consumption. Indeed, Bond and Westbrook (1982) found that greater preexposure to a saccharin taste decreased subsequent neophobic reaction to that taste. In addition, the co-joint occurrence of salt and morphine may alter attention (or salience) to the salt cue (see, e.g., Frey \& Sears, 1978). If morphine increases attention to salt, this enhanced attention may interfere with familiarization to the saccharin component of the cocktail. Hence, the novelty of the saccharin would again be greater for the morphine-paired group than for the control group.

Second, because the control groups never experienced morphine, the decreased saccharin intake in the morphinepaired group following second-order conditioning may have been due to differential exposure to morphine. That is, if the control group experienced equivalent morphine in the salt-conditioning phase, albeit unpaired with salt, the saccharin consumption for this explicitly unpaired control would have matched the morphine-paired group. We examined these alternative explanations in the next two experiments.

\section{EXPERIMENT 3}

In Experiment 3 we sought to replicate the secondorder conditioning results of Experiment 2 and to examine whether neophobia was responsible for the lower saccharin consumption in morphine-paired rats (i.e., secondorder conditioning).

\section{Method}

\section{Subjects and Apparatus}

The subjects were 27 male Sprague-Dawley rats weighing 310$357 \mathrm{~g}$ at the onset of the current experiment. The apparatus was unchanged.

\section{Procedure}

Initial training and salt conditioning. The initial training and group assignment ( $n=9$ per group) were the same as in Experiment 2 . In the salt-conditioning phase, one group (Paired) received the $1.5 \%$ salt CS paired with a $15 \mathrm{mg} / \mathrm{kg}$ injection of morphine. The other two groups, Saline and Neophob, received the same salt cue followed by saline. Conditioning was identical to that in Experi- 
ment 2 except that two additional trials were given (six trials total). Extra conditioning allowed us to examine whether direct salt aversion would emerge with further morphine pairings.

Second-order conditioning. Salt conditioning was followed by 2 days of second-order conditioning. On each of these 2 days, rats in Group Paired and Group Saline received 15-min access to a cocktail solution containing $0.1 \%$ saccharin and $1.5 \%$ salt. Group Neophob continued to receive $15-\mathrm{min}$ access to the $1.5 \%$ salt solution. Group Neophob provided an index of saccharin neophobia. That is, the first saccharin-alone test (see below) would be the first time this group experienced the saccharin taste. Neophobia would be evidenced if this group drank less saccharin than did Group Saline.

Saccharin test. All rats then received four saccharin tests in which a $0.1 \%$ saccharin solution was presented for $15 \mathrm{~min}$. Immediately following fluid access, each rat was given a $10-\mathrm{mg} / \mathrm{kg}$ intraperi toneal injection of lithium carbonate. Each saccharin test was separated by 2 intervening water days. Our decision to use lithium carbonate rather than morphine was governed by two reasons. First, using lithium carbonate as the illness-inducing US should avoid the apparent morphine tolerance observed in Experiment 2. Second, previous work in this laboratory has indicated that this low dose of lithium carbonate yields slow acquisition of conditioned saccharin aversion (Bardo \& Valone, 1994). If acquisition is slow in this phase, we may have a good chance of detecting second-order conditioning effects across several trials. Lithium carbonate (Fisher Scientific Co., Fair Lawn, NJ) was diluted in distilled water.

\section{Results}

Salt conditioning and second-order conditioning. Even with two additional conditioning trials, taste aversion did not develop to the salt $\mathrm{CS}(F<1$; see top panel of Figure 4). The bottom panel of Figure 4 shows the second-order conditioning data for Groups Paired and Saline. A repeated measures ANOVA revealed a main effect of measure $[F(1,16)=35.83]$, denoting an increase in cocktail consumption across trials. The group $\times$ measure interaction approached statistical significance $[F(1,16)=4.20, p=.057]$, indicating a slightly faster increase in intake for Group Saline. The main effect of group was not significant $(F<1)$.

Saccharin test. The use of lithium carbonate, instead of morphine, appeared to circumvent the tolerance effect seen in the last phase of Experiment 2. For each group, saccharin intake decreased slowly across the four conditioning trials (Figure 5). This pattern differed for rats that had had the saccharin taste previously paired with the morphine-conditioned salt cue (i.e., Group Paired). There was a main effect of measure $[F(3,72)=198.06]$ and a significant group $\times$ measure interaction $[F(6,72)=$ 4.69]. The main effect of group was not significant $(F<1)$. At each trial, orthogonal contrasts were conducted to confirm the source of the interaction and to assess a priori predictions. If a neophobic reaction was contributing to intake suppression in Group Paired, then we would expect Group Neophob to drink less saccharin than Group Saline. There was no statistical difference between these groups on any trial $(T \mathrm{~s} \leq 1.11)$. To assess whether Group Paired evidenced second-order conditioning relative to controls, we compared Group Paired and Group Neophob and Saline combined on each trial. Group Paired drank significantly less saccharin on the first conditioning trial $(T=2.90)$. Although this difference in consumption was
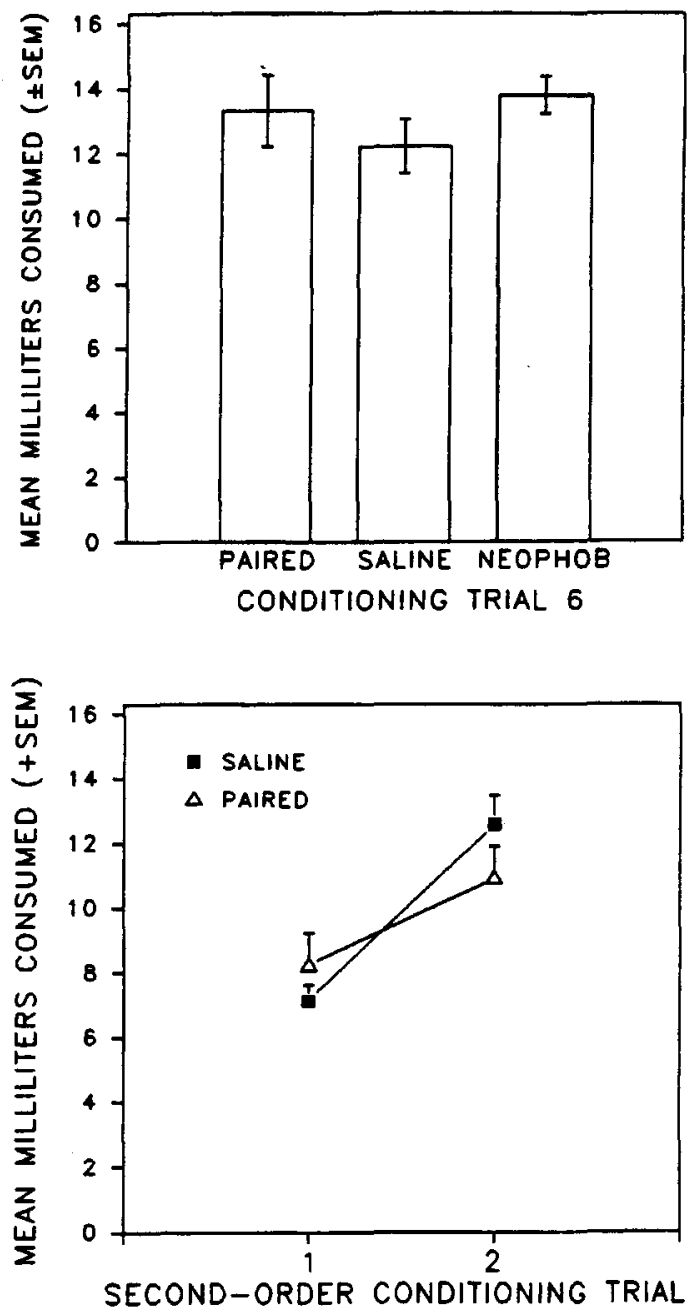

Figure 4. The top panel shows the salt consumption data for the three treatment groups of Experiment 3 on the last saltconditioning day. The bottom panel shows the saccharin + salt intake results for Groups Paired and Saline from the second-order conditioning phase of Experiment 3.

not significant for Trials 2 and $3(T \mathrm{~s}<1)$, it approached significance on the last trial $(T=1.99, p=.058)$.

\section{Discussion}

Experiment 3 was the fourth attempt to directly demonstrate conditioned salt aversion. We again failed to find direct evidence for conditioned salt aversion. In the secondorder conditioning phase, the decrease in saccharin + salt intake for morphine-paired rats was not replicated. The findings of the saccharin-alone test in Experiment 3, like those of Experiment 2, suggest that the salt CS paired with morphine did acquire conditioned aversive properties despite our failure to detect conditioning directly. The main evidence for conditioned salt aversion was that rats that had had saccharin paired with the previously conditioned salt CS (i.e., Group Paired) consumed less saccharin on the first trial than did the controls. This decrease was not due to a neophobic reaction to saccharin. Rats 


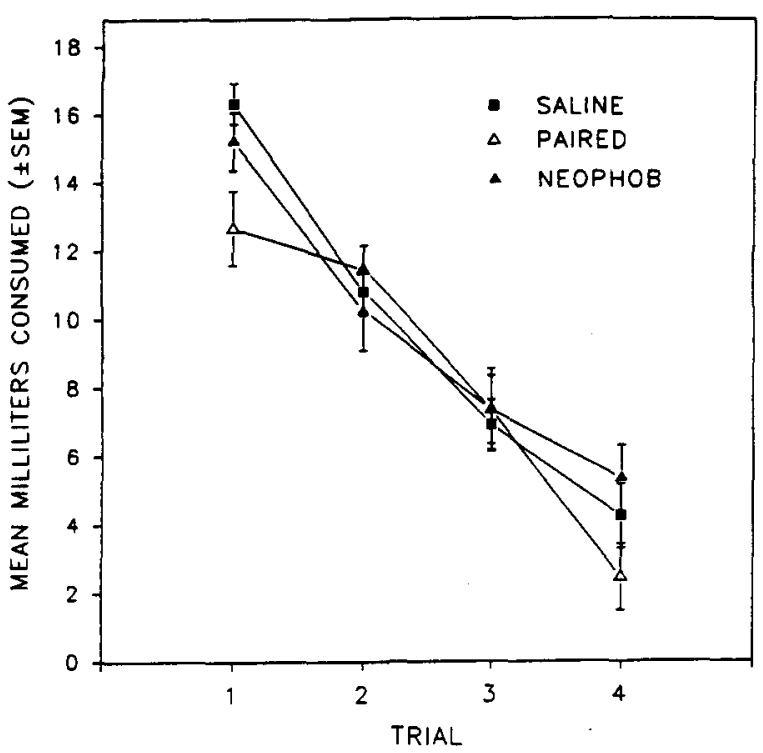

Figure 5. The saccharin consumption data across repeated trials in the saccharin test phase of Experiment 3. On each trial, saccharin was paired with lithium carbonate $(10 \mathrm{mg} / \mathrm{kg})$.

that had never experienced saccharin (Group Neophob) consumed as much saccharin solution as did Group Saline and more than did Group Paired.

\section{EXPERIMENT 4}

Up to this point, we have used saline controls in the present experiments. Thus, the control groups were not equated with the morphine-paired groups for experience with morphine. Although previous work in this laboratory has demonstrated that mere exposure to morphine was not responsible for saccharin-elicited aversion or analgesia (Bardo \& Valone, 1994), it may be responsible for the evidence of conditioning to the second-order saccharin cue. In Experiment 4 we examined this possibility by using an explicitly unpaired control rather than the saline control used in the previous experiments.

\section{Method}

\section{Subjects and Apparatus}

The subjects were 20 male Sprague-Dawley rats $(n=10$ per group) similar to those described in Experiment 1. The apparatus was unchanged.

\section{Procedure}

Unless otherwise noted, the procedural details were identical to those in Experiment 2. Initial training and group assignment proceeded as described previously. In the salt-conditioning phase, one group (Paired) received the $1.5 \%$ salt CS paired with a $15 \mathrm{mg} / \mathrm{kg}$ injection of morphine. The explicitly unpaired control group (Unpaired) received the same salt cue followed by saline. On the intervening water days, Group Paired was given $15-\mathrm{min}$ access to water followed by a saline injection; Group Unpaired was given morphine following water access. As in Experiment 2, there were 4 salt days and 4 water days. Salt conditioning was followed by 2 days of secondorder conditioning. On the day after the second-order conditioning phase, all rats received a single saccharin test in which a $0.1 \%$ saccharin solution was presented for $15 \mathrm{~min}$.

\section{Results and Discussion}

As in the previous experiments, there was no direct evidence for salt aversion $(F<1$; see top panel of Figure 6). The bottom panel of Figure 6 shows the intake of the saccharin + salt compound in the second-order conditioning phase. There was a main effect of trial $[F(1,18)=$ 8.28 , denoting an increase in consumption across trials. However, the main effect of group and the group $\times$ trial interaction were not significant $(F \mathrm{~s}<1)$. This latter result represents the second failure to replicate the decrease in intake of the saccharin + salt compound in the morphine-paired rats of Experiment 2. Procedural differences among the experiments may explain this discrepancy. Experiment 3 had six salt-conditioning trials, whereas Experiment 2 had only four trials. Perhaps the effect seen in Experiment 2 was transient. One difficulty
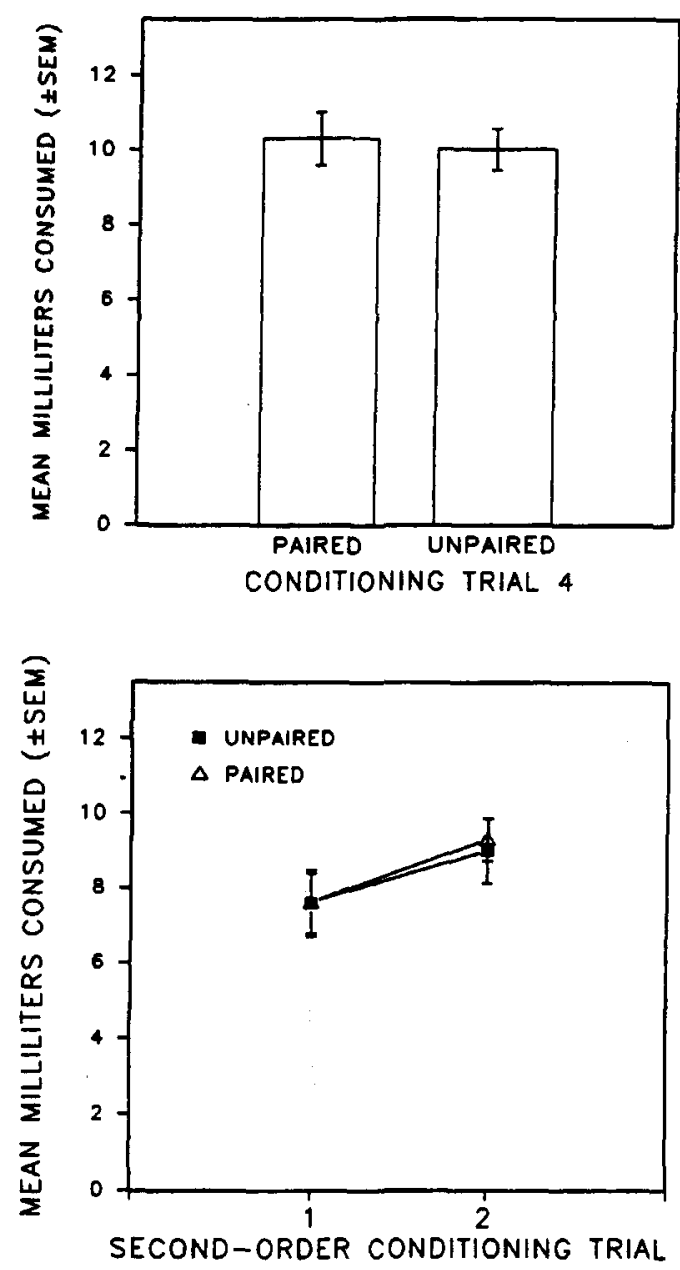

Figure 6. The top panel shows the salt intake on the last conditioning trial in Experiment 4. The bottom panel shows the saccharin + salt intake results from the second-order conditioning phase. 
with this interpretation, however, is that the present experiment had four salt conditioning trials and it, too, failed to replicate the second-order conditioning results of Experiment 2. However, unlike Experiment 2, the present experiment featured an unpaired morphine control group. Thus, Experiments 3 and 4 combined suggest that a shortlived nonassociative effect of morphine experience may be responsible for the discrepancy among experiments in the results of the second-order conditioning phase.

Evidence for second-order conditioning was found on the saccharin test day. Rats in Group Paired drank less saccharin solution than did the rats in Group Unpaired $[F(1,18)=5.80$; Figure 7]. Because both groups were exposed equally to morphine, the second-order conditioning evidence for salt aversion in the present experiment cannot be attributed to experiencing morphine in the salt-conditioning phase. Instead, pairing of morphine with the salt cue was important for demonstrating a decrease in consumption of the second-order saccharin CS.

\section{GENERAL DISCUSSION}

A $0.1 \%$ saccharin CS paired with a morphine US produced reliable and robust conditioned taste aversion (Experiment 1). However, different concentrations of a salt cue $(1 \%, 1.5 \%$, and $2 \%)$ paired with the same morphine US produced no conditioned salt aversion as assessed in a direct one-bottle test. Yet, a second-order conditioning procedure revealed unexpressed morphine-induced salt aversion in three separate experiments. Rats that received a novel saccharin taste paired in compound with the previously conditioned salt CS consumed less of the secondorder saccharin CS than did saline, neophobia, and explicitly unpaired controls. This data pattern may reflect a conditioned aversion directly acquired and elicited by the saccharin cue (i.e., second-order conditioning). However, we would expect the same results if a within-compound

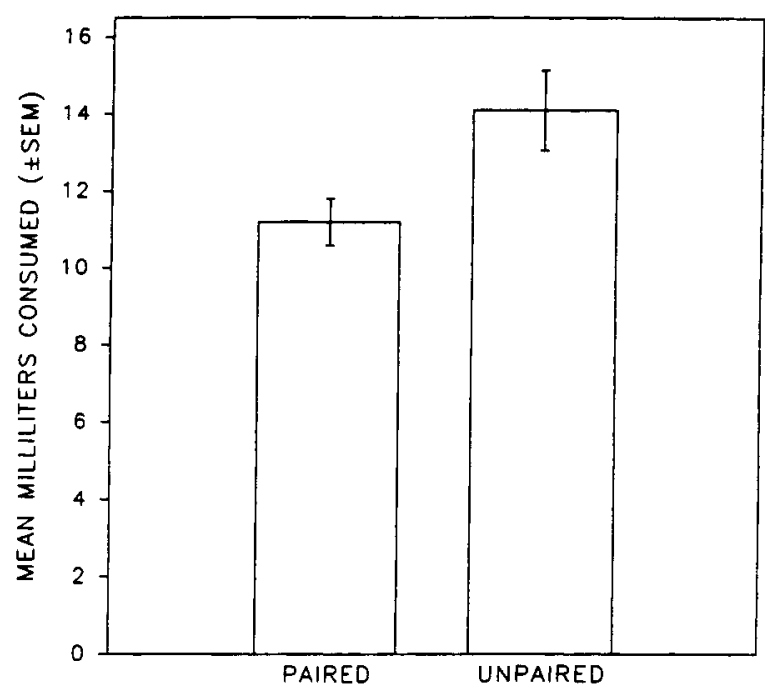

Figure 7. The saccharin consumption for Groups Paired and Unpaired in the saccharin test of Experiment 4. association between the salt and saccharin taste was formed (Holland, 1982). In this case, the decrease in saccharin intake would be due to an indirect association between saccharin and the aversive properties of the morphine US. That is, presentation of saccharin would activate a saccharin- salt association that, in turn, would activate the previously acquired salt-morphine association.

Both the within-compound association and the secondorder conditioning account require that saccharin be presented temporally contiguous with the salt cue. Although Experiment 4 established that the salt-morphine pairing was necessary for the subsequent decrease in saccharin intake, the present report has not demonstrated that the co-joint occurrence of saccharin and salt (i.e., the secondorder conditioning phase) is necessary for that effect. Generalized aversion from the salt to the saccharin taste is one possible mechanism that does not require the saccharin-salt pairing. Indeed, saccharin and salt share a sodium component.

Consideration of the mechanisms by which a saccharin aversion was expressed raises two related questions: (1) Why was morphine-conditioned salt aversion not directly expressed? (2) Why was the second-order conditioning procedure effective at detecting salt aversion? As for Question 1, the concentration-dependent intake of Experiment 2 (i.e., less intake of the $2 \%$ salt solution) argues against the possibility that the salt concentrations were too weak to be perceived. Moreover, unpublished data from our laboratory, as well as published reports from other laboratories (e.g., Bouton et al., 1987; Kalat \& Rozin, 1970; Schachtman et al., 1992), demonstrate robust lithium-induced taste aversion at salt concentrations of $1.5 \%$ and lower.

It may be argued that the morphine US $(15 \mathrm{mg} / \mathrm{kg})$ was too weak to condition a salt aversion. Although we did not conduct a dose-effect experiment examining higher doses of morphine, this explanation seems unlikely, as $15-\mathrm{mg} / \mathrm{kg}$ morphine in rats can condition a saccharin aversion, as in Experiments 1 and 2 (see Figure 3, right panel; see also Bevins et al., 1995). Furthermore, morphine doses as low as $3 \mathrm{mg} / \mathrm{kg}$ can induce a saccharin aversion (Bardo \& Valone, 1994; Cappell et al., 1973).

The tastes present in the rats' daily diet, however, may provide an explanation of the failure to find direct expression of a salt aversion. The rats in the present work were maintained on PROLAB Animal Diet (Rat, Mouse, Hamster 3000; Agway Inc., Syracuse, NY). Salt is one of the ingredients in this food. Thus, before the start of the study, the rats had had exposure to a "salty taste." Also, the laboratory chow was available throughout the experiment. To the extent that the food had a salty component that generalized to the salt solution, each eating bout before the study might have constituted preexposure to the salt CS, whereas each bout after the first conditioning trial might be considered extinction. Preexposure to a CS has been shown to attenuate subsequent conditioned responding to that cue (i.e., latent inhibition; Ayres, Philbin, Cassidy, Bellino, \& Redinger, 1992; Lubow, 1973). Also, each unpaired presentation of a previously conditioned 
stimulus (i.e., extinction) tends to weaken conditioning to that cue (Pavlov, 1927; Rescorla \& Wagner, 1972). Finally, the degree of taste aversion appears directly correlated with the relative novelty of the to-be-conditioned taste cue (Kalat, 1974; Kalat \& Rozin, 1970). Although it is not clear how relative novelty differs from CS preexposure, salt's novelty would be relatively low according to this formulation. These factors, combined with morphine's weak emetic ability, would work against the salt CS acquiring strong aversive conditioning.

Another possible explanation for the failure to directly detect salt aversion is that the hypertonic quality of the salt solution used in the present experiments may have interfered with the expression of a taste aversion. The hypertonic salt solution may have increased the waterdeprived state of the rats during each salt trial. If so, then the salt solution could have induced excessive drinking that competed with avoidance tendencies conditioned by the morphine US, thus preventing us from detecting a salt aversion in a direct one-bottle test.

This hypertonic explanation may also provide an answer for why the second-order conditioning procedure was able to detect unexpressed salt aversion (i.e., Question 2). Although the salt aversion was not directly expressed, presumably there was a strong association between the salt CS and the morphine US. Moreover, the low-concentration saccharin solution used as a secondorder CS does not have the hypertonic quality of the firstorder salt solutions used in the present work. Thus, regardless of the mechanism by which saccharin acquired its conditioned aversion, that aversion would be more readily detected. That is, the saccharin solution would not induce excessive drinking that would interfere with any avoidance tendencies acquired in the previous conditioning phases.

The dietary explanation described earlier does not provide as clear an answer about why the second-order procedure was a more sensitive index of salt aversion than a direct test. It may be that any alternative detection procedure would have provided evidence for a conditioned salt aversion. For example, in many situations a two-bottle preference test has been shown to be a more sensitive procedure for indexing taste aversions than a one-bottle test (e.g., Dragoin, McCleary, \& McCleary, 1971; Grote \& Brown, 1971; but see Batsell \& Best, 1993). If so, then a two-bottle preference test between the water and the salt solution used here might have revealed a decrease in preference for the salt solution in rats given salt-morphine pairings relative to controls (i.e., salt aversion).

Other procedures besides second-order conditioning have been used to assess whether apparent learning failures or deficits may instead reflect partial to complete performance deficits. Among the procedures employed for this purpose are summation (Rescorla, 1969), blocking (Kamin, 1969), and retention intervals (Kraemer \& Roberts, 1984; see R. R. Miller \& Grahame, 1991, for a more thorough discussion). Using these and other procedures, researchers have discovered that such classic phenomena as latent inhibition, blocking, and overshadowing, once presumed to be learning failures, appear to reflect, in part, performance deficits (Balaz, Gutsin, Cacheiro, \& R. R. Miller, 1982; Kasprow, Cacheiro, Balaz, \& R. R. Miller, 1982; Kraemer \& Roberts, 1984).

\section{REFERENCES}

Ayres, J. J. B., Philbin, D., Cassidy, S., Bellino, L., \& Redlinger, E. (1992). Some parameters of latent inhibition. Learning \& Motivation, 23, 268-287.

Balaz, M. A., Gutsin, P., Cacheiro, H., Miller, R. R. (1982). Blocking as a retrieval failure: Reactivation of associations to a blocked stimulus. Quarterly Journal of Experimental Psychology, 37B, 99-113.

BARDO, M. T., \& VALONE, J. M. (1994). Morphine-conditioned analgesia using a taste cue: Dissociation of taste aversion and analgesia. Psychopharmacology, 114, 269-274.

BATSELL, W. R., JR., \& BeST, M. R. (1993). One bottle too many? Method of testing determines the detection of overshadowing and retention of taste aversions. Animal Learning \& Behavior, 21, 154-158.

BEvins, R. A. (1992). Selective associations: A methodological critique. Psychological Record, 42, 57-73.

Bevins, R. A., Valone, J. M., Bradley, M., \& Bardo, M. T. (1995). Morphine taste conditioning and analgesia: Assessing conditioned and novelty-induced analgesia. Experimental \& Clinical Psychopharmacology, 3, 9-14.

Bond, N. W., \& Westbrook, R. F. (1982). The role of amount consumed in flavor preexposure effects and neophobia. Animal Learning \& Behavior, 10, 511-515.

Bouton, M. E., Dunlap, C. M., \& Swartzentruber, D. (1987). Potentiation of taste by another taste during compound aversion learning. Animal Learning \& Behavior, 15, 433-438.

Cappell, H., \& LeBlanC, A. E. (1975). Conditioned aversion by psychoactive drugs: Does it have significance for an understanding of drug dependence? Addictive Behaviors, 1, 55-64.

Cappell, H., \& LeBlanc, A. E. (1977). Parametric investigations of the effects of prior exposure to amphetamine and morphine on conditioned gustatory aversion. Psychopharmacology, 51, 265-271.

Cappell, H., LeBlanc, A. E., \& ENDrenyi, L. (1973). Aversive conditioning by psychoactive drugs: Effects of morphine, alcohol, and chlordiazepoxide. Psychopharmacologic, 29, 239-246.

DOMJAN, M. (1977). Attenuation and enhancement of neophobia for edible substances. In L. M. Barker, M. R. Best, \& M. Domjan (Eds.), Learning mechanisms in food selection (pp. 151-197). Waco, TX: Baylor University Press.

Dragoin, W., McCleary, G. E., \& McCleary, P. (1971). A comparison of two methods of measuring conditioned taste aversions. $\mathrm{Be}$ havior Research Methods \& Instrumentation, 3, 309-310.

Dugas du Villard, X., Her, C., \& MacLeod, P. (1981). Qualitative discrimination of sweet stimuli: Behavioural study on rats. Chemical Senses, 6, 143-148.

FREY, P. W., \& SEARS, R. J. (1978). Model of conditioning incorporating the Rescorla-Wagner associative axiom, a dynamic attention process, and a catastrophe rule. Psychological Review, 85, 321-340.

GAMzU, E., VincENT, G., \& BofF, E. (1985). A pharmacological perspective of drugs used in establishing conditioned food aversions. In N. S. Braveman \& P. Bronstein (Eds.), Experimental assessments and clinical applications of conditioned food aversions (Annals of the New York Academy of Sciences, Vol. 443, pp. 23 1-249). New York: New York Academy of Sciences.

Garcia, J., \& Koelling, R. A. (1966). Relation of cue to consequence in avoidance learning. Psychonomic Science, 4, 123-124.

Grote, F. W., JR., \& Brown, R. T. (1971). Conditioned taste aversions: Two-stimulus tests are more sensitive than one-stimulus tests. $B e$ havior Research Methods \& Instrumentation, 3, 311-312.

HollaNd, P. C. (1982). Interelement associations in serial compound conditioning. In M. L. Commons, R. J. Herrnstein, A. R. Wagner (Eds.), Quantitative analyses of behavior: Acquisition (Vol. 3, pp. 323-345). Cambridge, MA: Ballinger.

Hunt, T., \& AmIT, Z. (1987). Conditioned taste aversion induced by self-administered drugs: Paradox revisited. Neuroscience \& Biobehavioral Reviews, 11, 107-130. 
Iwamoto, E. T., \& Williamson, E. C. (1984). Nicotine-induced taste aversion: Characterization and preexposure effects in rats. Pharmacology, Biochemistry \& Behavior, 21, 527-532.

KALAT, J. W. (1974). Taste salience depends on novelty, not concentration, in taste-aversion learning in the rat. Journal of Comparative \& Physiological Psychology, 86, 47-50.

KALAT, J, W., \& Rozin, P. (1970). "Salience": A factor which can override temporal contiguity in taste-aversion learning. Journal of Comparative \& Physiological Psychology, 71, 192-197.

Kamin, L. J. (1969). Predictability, surprise, attention and conditioning. In B. A. Campbell \& R. M. Church (Eds.), Punishment and aversive behavior (pp. 279-296). New York: Appleton-Century-Crofts.

Kasprow, W. J., Cacheiro, H., Balaz, M. A., \& Miller, R. R. (1982). Reminder-induced recovery of associations to an overshadowed stimulus. Learning \& Motivation, 13, 155-166.

KRAemer, P. J., \& Roberts, W. A. (1984). The influence of flavor preexposure and test interval on conditioned taste aversions in the rat. Learning \& Motivation, 15, 259-278.

LoLoRDo, V. M. (1979). Selective associations. In A. Dickinson \& R. A. Boakes (Eds.), Mechanisms of learning and motivation: A memorial volume to Jerzy Konorski (pp. 367-398). Hillsdale, NJ: Erlbaum.

LoLordo, V. M., \& Droungas, A. (1989). Selective associations and adaptive specializations: Food aversion and phobias. In S. Klein \& R. Mowrer (Eds.), Contemporary learning theories: Instrumental conditioning theory and the impact of biological constraints on learning (pp. 145-179). Hillsdale, NJ: Erlbaum

Lubow, R. E. (1973). Latent inhibition. Psychological Bulletin, 79, 398-407.

Miller, J. S., Kelly, K. S., Neisewander, J. L., McCoy, D. F., \& BARDO, M. T. (1990). Conditioning of morphine-induced taste aversion and analgesia. Psychopharmacology, 101, 472-480.

Miller, R. R., \& Grahame, N. J. (1991). Expression of learning. In L. Dachowski \& C. F. Flaherty (Eds.), Current topics in animal learning. Brain, emotion, and cognition (pp. 95-117). Hillsdale, NJ: Erlbaum.

MiLler, V. (1984). Selective association learning in the rat: Generality of response systems. Learning \& Motivation, 51, 58-84.

Nowlis, G. H., Frank, M. E., \& Pfaffmann, C. (1980). Specificity of acquired aversions to taste qualities in hamsters and rats. Journal of Comparative \& Physiological Psychology, 94, 932-942.

Pavlov, I. P. (1927). Conditioned reflexes (G. V. Anrep, Trans.) London: Oxford University Press.

ResCorla, R. A. (1969). Pavlovian conditioned inhibition. Psychological Bulletin, 72, 77-94.

REsCoRla, R. A., \& WAGNER, A. R. (1972). A theory of Pavlovian conditioning: Variations in the effectiveness of reinforcement and nonreinforcement. In A. H. Black \& W. F. Prokasy (Eds.), Classical con- ditioning II: Current research and theory (pp. 64-99). New York: Appleton-Century-Crofts.

Riley, A. L., \& Clarke, C. M. (1977). Conditioned taste aversion: A biography. In L. M. Barker, M. R. Best, \& M. Domjan (Eds.), Learning mechanisms in food selection (pp. 593-615). Waco, TX: Baylor University Press.

Riley, A. L., JacoBs, W. J., \& LoLordo, V. M. (1978). Morphineinduced taste aversions: A consideration of parameters. Physiological Psychology, 6, 96-100.

Schachtman, T. R., Kasprow, W. J., Meyer, R. C., Bourne, M. J., \& HART, J. A. (1992). Extinction of the overshadowing CS after overshadowing in conditioned taste aversion. Animal Learning \& Behavior, 20, 207-218.

Seligman, M. E. P. (1970). On the generality of the laws of learning. Psychological Review, 77, 406-418.

ShetTleworth, S. J. (1972). Constraints on learning. In D. S. Lehrman, R. A. Hinde, \& E. Shaw (Eds.), Advances in the study of behavior (pp. 1-68). New York: Academic Press.

Stewart, J., \& Eikelboom, R. (1978). Pre-exposure to morphine and the attenuation of conditioned taste aversion in rats. Pharmacology, Biochemistry \& Behavior, 9, 639-645.

Swank, M. W., Schafe, G. E., \& Bernstein, I. L. (1995). c-Fos induction in response to taste stimuli previously paired with amphetamine or $\mathrm{LiCl}$ during taste aversion learning. Brain Research, 673, 251-261.

VAN DER KoOY, D., \& PhILlips, A. G. (1977). Temporal analysis of naloxone attenuation of morphine-induced taste aversion. Pharmacology, Biochemistry \& Behavior, 6, 637-641.

WiSE, R. A., YoKel, R. A., \& DEWIT, H. (1976). Both positive reinforcement and conditioned aversion from amphetamine and from apomorphine in rats. Science, 191, 1273-1275.

Yamamoto, T., Shimura, T., Sako, N., Yasoshima, Y., \& Sakai, N. (1994a). Neural substrates for conditioned taste aversion in the rats. Behavioural Brain Research, 65, 123-137.

Yamamoto, T., Shimura, T., Sako, N., Yasoshima, Y., \& Sakai, N. (1994b). Some critical factors involved in formation of conditioned taste aversion to sodium chloride in rats. Chemical Senses, 19, 209-217.

\section{NOTE}

1. The error term was 15 instead of 16 because 1 rat in the saline group was lost due to an injection error.

(Manuscript received June 12, 1995; revision accepted for publication July 30,1995 .) 